\title{
A Case Control Study: Evaluation of Serum Vitamin D Levels and Vitamin B12 Levels in Vitiligo
}

Author

\section{Latha Srirama*}

Dept of Dermatology \& Veneral Diseases, Narayana Medical College Hospital Chintareddypalem

Nellore -524002, and Andhra Pradesh, India

Corresponding Author

\section{Dr Latha Sriram}

Assistant Professor, Department of Dermatology \& Veneral Diseases, Narayana Medical College Hospital, Chintareddypalem, Nellore-524003

Email: research.nmch@rediffmail.com

\begin{abstract}
Background: Vitiligo is a common, acquired, often heritable, multifactorial, polygenic pigmentary disorder. Low levels of Vitamin D, an essential hormone synthesized in the skin with diverse effects on immune system have been associated with several autoimmune diseases including vitiligo.

OBJECTIVES: To study the association of the serum levels of Vitamin B12 and D3 in patients with vitiligo vulgaris in a tertiary care centre.

Materials and Methods: This is a case-control study conducted over a period of four months that included 30 clinically diagnosed cases of vitiligo and 30 age and sex matched controls. The serum levels of Vitamin D3 and B12 levels were measured in all subjects by Chemiluminiscient immunoassay. Statistical analysis was conducted by using Student's $t$ test and Mann Whitney test of the data collected by questionnaire.

Results: The mean value of serum Vitamin D3 levels was 22.10, values in males being significantly lower among the cases compared to the controls. Mean value of serum vitamin B12 (348.6) was significantly decreased in vitiligo group as compared to controls.

Conclusions: The present study demonstrated that there is an association between low serum levels of Vitamin D3 and Vitamin B12 with Vitiligo respectively suggesting the screening of these parameters to be made routine in Vitiligo patients.

Keywords: Vitiligo, Vitamin B12, Vitamin D3
\end{abstract}

\section{Introduction}

Vitiligo is a common, acquired, often heritable, multifactorial, polygenic pigmentary disorder with a complex pathogenesis and prevalence of $0.5-1 \%$ of population ${ }^{1}$. It is characterized by depigmented macules on skin due to loss of melanocytes. ${ }^{2-4}$. The resulting depigmentation whenever involves the cosmetically obvious areas like face and limbs may result in psychosocial morbidity 3, 4. Extensive studies in China, India and Denmark have estimated its prevalence to be $0.093 \%$, $0.005 \%$ and $0.28 \%$ respectively, the highest prevalence of $8.8 \%$ being reported from Gujarat province of India ${ }^{2,3}$. The cause of disease is 
unknown, but there are different theories including autoimmune, genetic, toxic metabolites or oxidative stress, neural causes and the lack of melanocyte growth factors ${ }^{3}$.

Vitamin D is a fat soluble essential hormone synthesized in the skin on exposure to ultraviolet B (UVB) present in the sunlight responsible for bone and Calcium homoestasis exerting its effects via Vitamin D receptors (VDR). It is also known to have immunoregulatory role on Innate and Adaptive systems contributing to the immunotolerance of the cell structures. It has been shown that vitamin $\mathrm{D}$ may reduce the generation of certain cytokines like interleukins 2, 6, 12 and TNF $\alpha$. A lack of vitamin D may cause defective macrophage function ${ }^{5,6}$. It may be logical to consider the role of Vitamin D in vitiligo, as Vitiligo is considered to be primarily an autoimmune disease, an aberration of immune surveillance leading to dysfunction and destruction of melanocytes causing depigmentation.

Vitamin B 12 is a water soluble vitamin primarily synthesized by gut bacteria used by every cell of the body for metabolism. Vitamin B12 helps in conversion of homocysteine to methionine, its deficiency leading to accumulation of homocysteine. Breakdown of homocysteine leads to the production of reactive oxygen species, harmful free radicals and thus increased oxidative stress in the skin, all leading to destruction of melanocytes $^{7,8}$. It is believed that patients with vitiligo are more likely to have pernicious anemia and vitamin B12 deficiency, ${ }^{3,5}$. Vitamin B12 facilitates the conversion of folate to tetrahydrofolate, which is essential in various enzyme reactions ${ }^{6,9}$.

With this background, we conducted a casecontrol study to compare serum vitamin D3 and vitamin B12 levels between patients with vitiligo and controls.

\section{Materials and methods}

Total of 60 subjects with age ranging from 10 to 70 years were enrolled for the study comprising of 30 new clinically diagnosed patients of vitiligo and 30 controls from the outpatient department of Dermatology and Venereology of Narayana Medical college and hospital, Nellore, Andhra pradesh, India.

Exclusion criteria were as follows: age <10 years and > 70 years, patients suffering from major cardiovascular diseases, renal, hepatic and major gastrointestinal disorders, those on supplements of folic acid, vitamin B12 and vitamin D, pregnancy. All the individuals studied were subjected to a complete assessment of history and clinical examination including the extent of vitiligo, estimated by the rule of nine, distribution of the lesion, clinical type of vitiligo, and bilaterality of lesions. The activity of the disease was assessed as follows: stable disease- no change in the vitiligo lesions during the 3 months before the study as observed by the patient and progressive diseaseenlargement of already present lesions and/or the appearance of new lesions within the 3 months before the study as observed by the patient.

Serum vitamin D levels were measured via the electrochemiluminescence assay using commercial kits. Regarding serum vitamin D levels, the subjects were categorized into three groups: normal who had vitamin D levels $>30$ $\mathrm{ng} / \mathrm{ml}$; insufficient who had vitamin $\mathrm{D}$ levels between 20 to $30 \mathrm{ng} / \mathrm{ml}$; and deficient who had vitamin D levels $<20 \mathrm{ng} / \mathrm{ml}$. Serum Vitamin B12 levels were measured in both patients and controls by chemiluminescent assay. Vitamin B12 levels $<211 \mathrm{pg} / \mathrm{ml}$ were considered deficient, levels $\geq$ $211 \mathrm{pg} / \mathrm{ml}$ being considered normal.

Statistical analysis of the data was done using student's t-test for difference of mean of vitamin B12 and Vitamin D on SPSS for windows (version 16.0) statistical package (SPSS Inc., Chicago, IL) computer statistics program. Comparisons between vitamin D levels on one hand and sex, age, and time of onset of disease on the other hand were made using Mann Whitney test. $\mathrm{P}$ values $\leq 0.05$ was taken to be statistically significant with a confidence level of $95 \%$. 


\section{JMSCR Vol||04||Issue||04||Page 10331-10336||April}

\section{Results}

The range of age of the sample included under the study was $10-70$ years, the mean age of vitiligo patients and controls being $43.9 \pm 14.60$ and $49.8 \pm 16.00350$ years respectively. Among the thirty vitiligo cases, 11 were males and 19 were females. [Table 1]

The mean value of serum vitamin B12 among the cases was $348.6 \pm 134.90$ which was sufficiently lower when compared to the controls included under the study (479.88 \pm 299.4$)$. There was a statistically significant difference between the cases and controls regarding the same as evident by the $p$ value of 0.000 . [Table 1]

Mean values of serum vitamin D3 were $22.10 \pm 13.05$ and $24.23 \pm 13.19$ among the cases and controls respectively. This finding of increased number of cases with significantly lower values of Vitamin D3 as compared to the controls was statistically significant ( $\mathrm{p}$ value 0.000). [Table 1]

Regarding the sex of the patients, the mean value of vitamin B12 level was higher in male compared to the female patients without statistical significance $(349.5 \pm 132.62$ Vs $344.9 \pm 138.52)$. Similarly the mean value of Vitamin D serum level was higher among the males in comparison with the females, but without statistical significance $\quad(24.51 \pm 14.25 \quad$ Vs 21.15 \pm 12.98$)$. [Table 2]

Statistically significant association between low levels of Vitamin D3 with Vitiligo has been more readily observed among the males compared to the females ( $p$ values 0.04 Vs 0.12). [Table 3]

Statistically significant association has been observed between duration of disease and deficiency of vitamin B12 (p value 0.039), but not with deficiency of Vitamin D3 ( $p$ value 0.532). [Table 4]

Table 1: Serum levels of vitamin B12 and Vitamin D3 in vitiligo and controls

\begin{tabular}{|l|l|l|}
\hline Groups & $\begin{array}{l}\text { Vitamin B12 } \\
\text { Mean } \pm \text { SD }(\mathrm{pg} / \mathrm{ml})\end{array}$ & $\begin{array}{l}\text { Vitamin D } \\
\text { Mean } \pm \text { SD }(\mathrm{ng} / \mathrm{ml})\end{array}$ \\
\hline Cases & $348.6 \pm 134.90$ & $22.10 \pm 13.05$ \\
\hline Controls & $479.88 \pm 299.4$ & $24.23 \pm 13.19$ \\
\hline P value & 0.000 & 0.000 \\
\hline
\end{tabular}

Table 2: Serum levels of vitamin B12 and Vitamin D3 in male and female cases

\begin{tabular}{|l|l|l|}
\hline Groups & $\begin{array}{l}\text { Vitamin B12 } \\
\text { Mean } \pm \text { SD }(\mathrm{pg} / \mathrm{ml})\end{array}$ & $\begin{array}{l}\text { Vitamin D } \\
\text { Mean } \pm \text { SD }(\mathrm{ng} / \mathrm{ml})\end{array}$ \\
\hline Males (11) & $349.5 \pm 132.62$ & $24.51 \pm 14.25$ \\
\hline Females (19) & $344.9 \pm 138.52$ & $21.15 \pm 12.98$ \\
\hline P value & 0.852 & 0.758 \\
\hline
\end{tabular}

Table 3: Sexual distribution of serum levels of Vitamin D3 in cases and controls

\begin{tabular}{|l|l|l|l|}
\hline Groups & Vitiligo cases & Controls & P value \\
\hline Males (11) & $21.24 \pm 12.48$ & $24.59 \pm 12.86$ & 0.04 \\
\hline Females (19) & $23.56 \pm 13.12$ & $24.12 \pm 13.17$ & 0.12 \\
\hline
\end{tabular}

Table 4: Correlation of serum vitamin B12 and Vitamin D3 with duration of disease

\begin{tabular}{|l|l|l|l|}
\hline Duration of disease (years) & $\begin{array}{l}\text { Total (30) } \\
\text { No }(\%)\end{array}$ & $\begin{array}{l}\text { Vitamin B12 } \\
\text { Mean } \pm \text { SD }(\mathrm{pg} / \mathrm{ml})\end{array}$ & $\begin{array}{l}\text { Vitamin D3 } \\
\text { Mean } \pm \text { SD }(\mathrm{ng} / \mathrm{ml})\end{array}$ \\
\hline$\leq 1$ & 13 & $421.96 \pm 125.70$ & $24.28 \pm 14.22$ \\
\hline $2-5$ & 14 & $370.54 \pm 125.07$ & $23.59 \pm 13.27$ \\
\hline$>5$ & 3 & $342.56 \pm 59.61$ & $22.26 \pm 12.41$ \\
\hline P value & $0.039^{*}$ & 0.532 \\
\hline
\end{tabular}




\section{Discussion}

Vitiligo is a common, multifactorial, polygenic pigmentary disorder with a complex pathogenesis and psychological morbidity. It may be logical to consider the role of Vitamin $\mathrm{D}$, an immunoregulatory hormone in vitiligo, as Vitiligo is considered to be primarily an autoimmune disease, an aberration of immune surveillance leading to dysfunction and destruction of melanocytes causing depigmentation. Vitamin B 12 is a water soluble vitamin involved in oxidation and antioxidation system through homocyteine- methionine pathway. Breakdown of homocysteine leads to the production of reactive oxygen species, harmful free radicals and thus increased oxidative stress in the skin, all leading to destruction of melanocytes ${ }^{8}$. It is believed that patients with vitiligo are more likely to have pernicious anemia and vitamin B12 deficiency ${ }^{8,10}$. The finding of range of age of the sample included in the current study (10 to 70 years) is in accordance with the existing reports of the age distribution of vitiligo ${ }^{11}$. The mean age of vitiligo patients and controls was $43.9 \pm 14.60$ and $49.8 \pm 16.00350$ years respectively. [Table 1] Mean values of serum vitamin D3 were $22.10 \pm 13.05$ and $24.23 \pm 13.19$ among the cases and controls respectively. This showed the increased association of Vitiligo cases with deficiency of Vitamin D 3 in a statistically significant manner ( $p$ value 0.000 ). [Table 1] This finding concorded with the Silverberg JI et al, and $\mathrm{Xu} \mathrm{X}$, et al. study, which showed a deficient level of Vitamin D3 in Vitiligo patients, without statistical significance $^{12,13}$. This finding coincided with a case report Nunes JP etal, which showed low levels of vitamin $\mathrm{D}$ (equal to $12 \mathrm{ng} / \mathrm{mL}$ ) to be associated with vitiligo patient ${ }^{14}$.

Despite lower serum levels of vitamin D in women, there was no statistically significant relationship between sex and serum vitamin D levels in our study. However, when compared to healthy men, serum vitamin D levels were significantly lower in male patients with vitiligo. [Table 2, Table 3] This finding correlated with findings of Khurram et al study and Xu X et al. ${ }^{13}$,

15. On the other hand, there was no significant difference between serum vitamin D levels between the women in case and control groups, that can be explained by their reduced duration of sun exposure compared to males, on account of their remaining indoors.

In our study we found that there was a significant decrease in serum vitamin B12 levels in vitiligo cases when compared to controls. This finding coincides with Singh $S$ et al study and Karadag As et al study but not with Yasar Ali et $\mathrm{al}^{16-18}$. Sex did not affect the levels of vitamin B12 in the current study. This is in accordance with the studies of Montes et al ${ }^{7,8}$, Batawi et al ${ }^{8}$ Singh S et al ${ }^{16}$ and Gonul et $\mathrm{al}^{19}$.

Statistically significant association has been observed between duration of disease and deficiency of vitamin B12 (p value 0.039). This finding coincided with the findings of Singh $S$ et al. $^{20}$ There was no statistically significant association between the duration of disease and Vitamin D3 deficiency ( $p$ value 0.532). [Table 4] Measurement of serum levels of vitamin D3 and B12 at the time of diagnosis of vitiligo is recommended and their supplementation is suggested to those suffering from the deficiencies of the same. Further studies with larger sample size and cohort studies are recommended to investigate the effects of vitamin D 3 and B12 deficiency and their supplementation on the incidence of vitiligo.

\section{Conclusion}

Nutritional deficiencies of Vitamin D3 and B12 can be considered as precipitating factors in the pathogenesis of vitiligo in predisposed individuals due to their role in free radical mediated damage of melanocytes. Hence we recommend routine screening for their deficiencies to prevent the occuence and progresiion of Vitiligo. 


\section{References}

1. Dave S, D'Souza M, Thappa DM, Reddy KS, Bobby Z. HIGH FREQUENCY OF THYROID DYSFUNCTION IN INDIAN PATIENTS WITH VITILIGO. Indian $\mathrm{J}$ Dermatol 2003;48(2):68-72.

2. Howitz J, Brodthagen $H$, Schwartz M, Thomsen K. Prevalence of vitiligo: epidemiological survey on the Isle of Bornholm, Denmark. Archives of dermatology 1977;113(1):47-52.

3. Das S, Majumder PP, Chakrabotry R, Majumdar T, Haldar B, Rao D. Studies on vitiligo I. Epidemiological profile in Calcutta, India. Genetic epidemiology 1985;2(1):71-78.

4. Dwivedi M, Laddha NC, Shajil E, Shah BJ, Begum R. The ACE gene I/D polymorphism is not associated with generalized vitiligo susceptibility in Gujarat population. Pigment cell \& melanoma research 2008;21(3):407-408.

5. Adorini L, Penna G. Control of autoimmune diseases by the vitamin D endocrine system. Nature clinical practice Rheumatology 2008;4(8):404-412.

6. Overbergh L, Decallonne B, Valckx D, et al. Identification and immune regulation of 25-hydroxyvitamin D-1- $\alpha$-hydroxylase in murine macrophages. Clinical \& Experimental Immunology 2000;120(1):139-146.

7. Montes LF, Diaz M, Lajous J, Garcia N. Folic acid and vitamin B12 in vitiligo: a nutritional approach. Cutis 92;50(1):39-42.

8. El-Batawi M, El-Tawil N, El-Tawil A. Serum levels of vitamin B12 and folic acid in Egyptian patients with vitiligo. Egypt J Derm Androl 2001;21:77-80.

9. De Haes $P$, Garmyn $M$, Degreef $H$, Vantieghem K, Bouillon R, Segaert S. 1, 25-dihydroxyvitamin D3 inhibits ultraviolet B-induced apoptosis, Jun kinase activation, and interleukin- 6 production in primary human keratinocytes. Journal of cellular biochemistry 2003;89(4):663-673.

10. Kim SM, Kim YK, Hann SK. Serum levels of folic acid and vitamin B12 in Korean patients with vitiligo. Yonsei medical journal 1999;40(3):195-198.

11. Mosher DB, Parrish JA, Fitzpatrick TB. Monobenzylether of hydroquinone. A retrospective study of treatment of 18 vitiligo patients and a review of the literature. $\mathrm{Br} \mathrm{J}$ Dermatol 1977;97(6):669-79.

12. Silverberg JI, Reja M, Silverberg NB. Regional variation of and association of US birthplace with vitiligo extent. JAMA Dermatol 2014;150(12):1298-305.

13. Xu X, Fu W-W, Wu W-Y. Serum 25hydroxyvitamin $\mathrm{D}$ deficiency in Chinese patients with vitiligo: a case-control study. PloS one 2012;7(12):e52778.

14. Nunes J, Martins CS. Myocardial infarction, hypovitaminosis D and vitiligo. Revista portuguesa de cardiologia: orgao oficial da Sociedade Portuguesa de Cardiologia $=$ Portuguese journal of cardiology: an official journal of the Portuguese Society of Cardiology 2010;29(5):839-840.

15. Alghamdi KM, Khurram H, Taieb A. Survey of dermatologists' phototherapy practices for vitiligo. Indian $\mathrm{J}$ Dermatol Venereol Leprol 2012;78(1):74-81.

16. Singh S, Singh U, Pandey SS. Increased level of serum homocysteine in vitiligo. Journal of clinical laboratory analysis 2011;25(2):110-112.

17. Karadag AS, Tutal E, Ertugrul DT, Akin KO, Bilgili SG. Serum holotranscobalamine, vitamin B12, folic acid and homocysteine levels in patients with vitiligo. Clin Exp Dermatol 2012;37(1):62-4.

18. Yasar A, Gunduz K, Onur E, Calkan M. Serum homocysteine, vitamin B12, folic acid levels and methylenetetrahydrofolate reductase (MTHFR) gene polymorphism 
in vitiligo. Disease markers 2012;33(2):85-

89.

19. Gonul M, Cakmak SK, Soylu S, Kilic A, Gul U. Serum vitamin B12, folate, ferritin and iron levels in Turkish patients with vitiligo. Indian $\mathbf{J}$ Dermatol Venereol Leprol 2010;76(4):448.

20. Singh S, Singh U, Pandey SS. Increased level of serum Homocysteine in vitiligo. $\mathrm{J}$ Clin Lab Anal 2011;25(2):110-2. 